University of Nebraska - Lincoln

DigitalCommons@University of Nebraska - Lincoln

Faculty Publications, Department of Psychology

Psychology, Department of

2017

\title{
Impact of child sexual abuse on non-abused siblings: A review with implications for research and practice
}

\author{
Alayna Schreier \\ University of Nebraska-Lincoln, alayna.schreier@gmail.com \\ Jessica K. Pogue \\ University of Nebraska - Lincoln, jpogue@unl.edu \\ David J. Hansen \\ University of Nebraska - Lincoln, dhansen1@unl.edu
}

Follow this and additional works at: https://digitalcommons.unl.edu/psychfacpub

Part of the Child Psychology Commons, Clinical Psychology Commons, Counseling Psychology

Commons, and the Developmental Psychology Commons

Schreier, Alayna; Pogue, Jessica K.; and Hansen, David J., "Impact of child sexual abuse on non-abused siblings: A review with implications for research and practice" (2017). Faculty Publications, Department of Psychology. 1007.

https://digitalcommons.unl.edu/psychfacpub/1007

This Article is brought to you for free and open access by the Psychology, Department of at DigitalCommons@University of Nebraska - Lincoln. It has been accepted for inclusion in Faculty Publications, Department of Psychology by an authorized administrator of DigitalCommons@University of Nebraska - Lincoln. 


\title{
Impact of child sexual abuse on non-abused siblings: A review with implications for research and practice
}

\author{
Alayna Schreier, Jessica K. Pogue, \& David J. Hansen \\ Department of Psychology, University of Nebraska-Lincoln, United States \\ Corresponding author — A. Schreier, alayna.schreier@gmail.com
}

\begin{abstract}
Research has widely supported the numerous negative outcomes for victims of child sexual abuse (CSA), but little attention has been paid to the experiences of nonabused, non-offending siblings following the victim's disclosure. This review presents evidence indicating that this overlooked sibling population merits both clinical and research attention. Siblings may experience significant emotional and behavioral responses to the victim's disclosure due to changes within the family system. A sibling's internalizing and externalizing behaviors can increase family distress post-abuse, while a supportive sibling can contribute to the victim's recovery. The current state of clinical services for siblings is described. Services including the entire family have been found to be especially beneficial in reducing the negative impact of CSA. Although siblings may present to treatment with subclinical symptoms of distress on average, there is a heterogeneity in emotional and behavioral responses similar to that found in victims. There are currently no measures designed to specifically capture the sibling's experience and impairment following the victim's CSA. Recommendations for future research are provided.
\end{abstract}

Keywords: Siblings, Child sexual abuse, Family violence

Published in Aggression and Violent Behavior 34 (2017) 254-262

DOI: 10.1016/j.avb.2016.11.011

Copyright (C) 2016 Elsevier Ltd. Used by permission.

Submitted 20 May 2016; accepted 29 November 2016. 


\section{Contents}

1. Introduction . . . . . . . . . . . . . . . . . . . . . . . . . . .2

1.1. Child sexual abuse . . . . . . . . . . . . . . . . . . . . . . . . . . . . . . . . . . . . . . . . . . . . . . . . . .

1.2. Sibling relationships . . . . . . . . . . . . . . . . . . . 4

2. Impact of child sexual abuse on siblings . . . . . . . . . . . . . . . . . . . . . . . . . 6

2.1. Siblings' emotional and behavioral responses . . . . . . . . . . . . 6

2.2. Family stress and disruption . . . . . . . . . . . . . . . . . . . . . . 9

2.3. Practical consequences . . . . . . . . . . . . . . . . . 10

2.4. Protective factors . . . . . . . . . . . . . . . . . . . . 12

3. Treatment approaches . . . . . . . . . . . . . . . . . . . . . . . . . . . 13

4. Challenges and recommendations for future directions . . . . . . . . . . 17

5. Conclusion . . . . . . . . . . . . . . . . . . . . . . . 20

References. . . . . . . . . . . . . . . . . . . . . 20

\section{Introduction}

Child sexual abuse (CSA) has received increasing attention over the past few decades given the myriad negative outcomes that significantly impact victims, including psychological distress, low self-esteem, externalizing behavior problems, and delinquent behavior (for reviews see Kendall-Tackett, Williams, \& Finkelhor, 1993; Maniglio, 2009; Putnam, 2003; Tyler, 2002). Non-offending caregivers are also impacted by CSA, often facing significant social and economic consequences including separation or divorce and financial loss (Corcoran, 2004; Elliott \& Carnes, 2001; Tavkar \& Hansen, 2011), along with emotional and psychological distress that may result in part from involvement with law enforcement or participation in civil or criminal litigation (Corcoran, 2004; Deblinger, Hathaway, Lippmann, \& Steer, 1993).

While there has been a substantial body of literature dedicated to the impact of CSA on victims and non-offending caregivers, little is known about the experience of CSA for non-abused, non-offending siblings (Hill, 2003; Swenson \& Hanson, 1998; Tavkar \& Hansen, 2011). Clinical case examples and anecdotal evidence suggest that non-abused siblings can experience a variety of negative emotional and psychological effects, such as confusion and guilt (Bentovin, 1991), along with more tangible consequences including changing schools, moving residences, or interacting with law enforcement (Baker, Tanis, \& Rice, 2001). These effects may be heightened if the offender is a member of the family unit, consistent with research on outcomes for victims of CSA (Stroebel et al., 2012). Siblings of sexually abused children are also at increased risk for 
experiencing later victimization themselves (Boney-McCoy \& Finkelhor, 1995; East, Chien, Adams, Hokoda, \& Maier, 2010; O’Brien, 1991). Further, sibling response to CSA can impact the victim's functioning and recovery, highlighting the importance of treatment and intervention in supporting family functioning as a whole. There is a paucity of literature on the implications of CSA for siblings.

To date, there are only two published papers specifically focused on this population (see Baker et al., 2001; Hill, 2003). Despite the broad effects of CSA on the family unit, the limited research has found that siblings tend to present as sub-clinical on measures designed to evaluate victim's emotional and psychological functioning following disclosures of CSA (Baker et al., 2001). Further, current treatments and interventions rarely include siblings and methodological limitations preclude robust examinations of effectiveness of those treatments in which they are included (Schreier et al., 2012). This paper first provides a background on both CSA and sibling relationships, intended to serve as a context for these dimensions in the subsequent review of the literature on the impact of CSA on siblings. Given the limited available research on this specific population, we will also extrapolate from other bodies of literature, including exposure to family violence, divorce, bereavement, and chronic illness. In some areas, we supplement the available research evidence with clinical perspectives gained from serving this population. We then describe the current state of clinical services for siblings, focusing on four existing treatments and describing one in detail. This broad look at relevant literatures and clinical experience is used to provide valuable directions for future research and clinical practice with nonabused siblings.

\subsection{Child sexual abuse}

To understand the context in which siblings experience the effects of CSA and its subsequent disclosure, it is important to understand CSA more broadly. Although methodological limitations and reliance on victim report preclude accurate estimates of prevalence, recent data suggest that approximately $24.7 \%$ of women and $16 \%$ of men experience sexual abuse in childhood (Centers for Disease Control and Prevention [CDC], 2010). National estimates of CSA incidence annually range from 0.83 to 2.4 per 1000 children (Friedenberg, Hansen, \& Flood, 2013; Sedlak et al., 2010; U.S. Department of Health and Human Services [U.S. 
DHHS], 2016). Between one third and one half of CSA is intrafamilial, or perpetrated by a family member, with most CSA victims reporting male perpetrators (Sedlak et al., 2010; Seto, Babchishin, Pullman, \& McPhail, 2015). Even in cases of extrafamilial CSA, the offender is typically known to the victim prior to the abuse (Friedenberg et al., 2013).

Children who experience CSA rarely disclose their abuse immediately. In a review of the literature, McElvaney (2015) found that the majority of CSA victims do not disclose their abuse until adulthood. Even among those who report their abuse in childhood, delayed disclosure is common, with estimates suggesting that between 19 and $47 \%$ of individuals fail to disclose within one year of abuse onset (Kogan, 2004; McElvaney, 2015; Smith et al., 2000). Delayed disclosure may be a result of many factors, including victim, offender, and abuse characteristics. Younger children are less likely to report their abuse soon after onset and are less likely to make explicit, purposeful disclosures (Collings, Griffiths, \& Kumalo, 2005; Jonzon \& Lindblad, 2004; Smith et al., 2000). A substantial body of literature has identified that children are less likely to disclose intrafamilial abuse (Goodman-Brown, Edelstein, Goodman, Jones, \& Gordon, 2003; McElvaney, 2015; Smith et al., 2000). It is likely that this delayed disclosure is due to fear of negative consequences or a desire to be loyal to family (Goodman-Brown et al., 2003; Hershkowitz, Lanes, \& Lamb, 2007). Findings have been mixed regarding the association between abuse severity and abuse duration on timing of disclosure (McElvaney, 2015).

\subsection{Sibling relationships}

There is a substantial body of research dedicated to the study of sibling relationships. This literature has long supported the notion that siblings play a significant role in development across the lifespan (e.g., Dunn, 2002; East, 2009; Howe, Ross, \& Rechhia, 2011; Solmeyer, McHale, $\&$ Crouter, 2014). Sibling relationships are ripe for opportunities to learn about interacting with the world due to the amount of time spent together as well as its involuntary nature that distinguishes it from other peer relationships (e.g., Dunn, 2002; Howe \& Recchia, 2014). Sibling relationships tend to be characterized by positive interactions measured by warmth and negative interactions measured by conflict (Buist, Dekovic, \& Prinzie, 2013; Gamble \& Yu, 2014; McGuire, McHale, \& Updegraff, 1996). Research has demonstrated continuity over time in the 
quality of sibling relationship (Dunn, Slomkowski, \& Beardsall, 1994; Slomkowski \& Manke, 2004). Although the quality of the relationship may be stable, the nature of the relationship changes over time. In early and middle childhood, the sibling relationship occurs primarily in the context of reciprocal interactions such as play, with the older sibling taking a more active role (Howe \& Recchia, 2005; Howe et al., 2011). As siblings age, the relationship becomes more egalitarian but may also become less of an influence due to greater involvement of peer groups (Buist et al., 2013).

The quality and characteristics of the sibling relationship also vary by nature of birth order, birth spacing, and sex (Solmeyer et al., 2014). Drawing from the early literature on social learning theory, research has suggested that older siblings serve as role models, influencing the development of younger siblings' empathy, social competence, and identity formation through complementary interactions (Dirks, Persram, Recchia, \& Howe, 2015; Howe \& Recchia, 2005; Tucker, Updegraff, McHale, \& Crouter, 1999; Wong, Branje, VanderValk, Hawk, \& Meeus, 2010). Sibling relationships can also be characterized by rivalry and jealousy; some literature has demonstrated that siblings may compete for attention and may become jealous due to differential attention from a caregiver (Buist et al., 2013; Dirks et al., 2015). In a study examining sibling social comparison, female siblings and siblings closer in age were more likely to engage in social comparison, though younger siblings were more likely to compare themselves to older siblings than vice versa (Jensen, Pond, \& Padilla-Walker, 2015). Siblings of the same sex tend to have greater warmth and closeness than opposite-sex siblings, particularly those closer in age, though siblings closer in age also tend to display higher levels of conflict (Buist et al., 2013; Furman \& Buhrmester, 1985).

Negative or conflictual sibling relationships have been associated with internalizing and externalizing symptomatology across the lifespan. Across childhood and adolescence, negative sibling relationships have been linked to greater levels of depressive symptoms and aggression and lower levels of social competence (Buist et al., 2013; Buist \& Vermande, 2014; Dirks et al., 2015; Whiteman, Solmeyer, \& McHale, 2015). In adolescence, a negative or conflictual sibling relationship has been associated with risky and antisocial behavior, including substance use and risky sexual behavior (Criss \& Shaw, 2005; Slomkowski, Rende, Conger, Simons, \& Conger, 2001; Solmeyer et al., 2014; Whiteman et al., 2015). However, the sibling relationship can also be protective (Buist et 
al., 2013; Gass, Jenkins, \& Dunn, 2007). Sibling relationships characterized by warmth have been shown to moderate the relationship between parental psychological distress and child adjustment (Keeton, Teetsel, Dull, \& Ginsburg, 2015). Further, supportive sibling relationships are associated with fewer depressive symptoms following stressful life events (Gass et al., 2007).

\section{Impact of child sexual abuse on siblings}

This section reviews the literature on the impact of child sexual abuse on siblings. For convenience and clarity, we have separated the various consequences of CSA into logical categories of emotional and behavioral responses, family stress and disruption, practical consequences, and protective factors. However, it is important to acknowledge that there are substantial interrelationships between each of these organizational categories. Hereafter, when we refer to siblings, we are referring to nonabused, non-offending siblings of sexually abused youth.

\subsection{Siblings' emotional and behavioral responses}

Consistent with the diverse symptom presentation displayed by CSA victims (Sawyer \& Hansen, 2014; Yancey, Hansen, \& Naufel, 2011), there is heterogeneity in siblings' emotional and behavioral responses to the aftermath of CSA disclosure. Siblings can experience a wide variety of problems including internalizing and externalizing symptoms (Pogue \& Hansen, 2016) and may engage in negative behaviors toward the victim and non-offending caregiver (e.g., anger, not believing the victim). The severity of the abuse, length of time that the abuse occurred, perpetrator's relationship to the family, location of the abuse, the sibling's age, disposition when faced with uncertainty and stress, and the closeness of the victim's relationship to the sibling may influence the sibling's emotional and behavioral response (Baker et al., 2001; Hill, 2003; Swenson \& Hanson, 1998).

Siblings may exhibit internalizing symptoms, such as anxiety, sadness, or depression following disclosure of CSA (Baker et al., 2001; Grosz, Kempe, \& Kelly, 2000; Hill, 2003; Pogue \& Hansen, 2016). Exploratory research has indicated that the higher the victim's level of distress following disclosure, the more likely the sibling is to report higher levels 
of distress (Pogue et al., 2014; Pogue \& Hansen, 2016). Although not directly linked to a sibling's reaction to CSA, exposure to intimate partner violence (IPV) has been associated with increased internalizing, externalizing, and trauma symptoms in childhood (Wathen \& MacMillan, 2013). Even the language of 'exposure to IPV' rather than 'witnessing IPV' reflects the evidence suggesting that the child does not need to be present in the room when the violence occurs to experience negative outcomes. As such, siblings may not need to physically witness the sexual abuse to experience the negative effects of CSA and its subsequent disclosure. For example, even if siblings are not told explicitly about CSA, they often know more than what the caregiver realizes and are aware that something traumatic has occurred in their family (Bentovin, 1991). It is also considered exposure to violence if a youth knows that threats were made against another person in the family (Lanius, Vermetton, \& Pain, 2010). In situations where CSA victims were threatened by the perpetrator, siblings may experience fear and feel unsafe. In a small sample of CSA victims and their siblings, a sibling's fears related to victimization were significantly correlated with sibling distress, suggesting that fear may be contributing to symptoms of depression and anxiety (Pogue \& Hansen, 2016). Further, it can be argued that some siblings may develop secondary trauma symptoms following disclosure of the victim's abuse (Pogue \& Hansen, 2016). Although the research on secondary trauma has focused on mental health professionals and responders (Levitt, Owen, \& Truchsess, 1991; Many \& Osofsky, 2012), one might extrapolate from the secondary trauma literature to suggest similar risks for siblings whose family frequently discusses abuse-specific information.

CSA victims commonly report feelings of embarrassment, humiliation, and shame, especially if the disclosure becomes public (Murray, Nguyen, \& Cohen, 2014). Victims may also receive negative reactions or stigma from those who do not believe them or those who are uncomfortable with someone who has experienced CSA (Graham, Rogers, \& Davies, 2007; Jonzon \& Lindblad, 2004). Siblings may be the recipients of these negative reactions themselves, but they are likely also affected by the negative reactions directed toward the victim. Similar stigma, including a "legacy of blame," may be faced by children whose parents have attempted or completed suicide (Hung \& Rabin, 2009, p. 793).

Older siblings in particular may feel guilty for a variety of reasons, including not having protected the victim (Baker et al., 2001; Grosz et al., 2000; Hill, 2003). Anecdotally, some siblings knew the abuse was 
occurring, either by witnessing the abuse directly or receiving the initial disclosure, and kept it a secret along with the victim. Siblings also report confusion, though the reasons for confusion vary (Grosz et al., 2000). Some siblings we have encountered in our clinical work have expressed confusion over why the victim was abused and they were not. In cases of intrafamilial abuse, the sibling may not understand why the perpetrator is no longer living with the family. Siblings may also struggle to believe that the perpetrator could have committed the abuse (Baker et al., 2001; Hill, 2003). This can be particularly challenging with intrafamilial abuse. Lipovsky, Saunders, and Hanson (1992) found that victims reported greater relationship difficulties with fathers who were offenders than did non-abused siblings. As such, the sibling may have a hard time understanding that the caregiver hurt the victim because they did not experience the same relationship difficulties. It is common for siblings to grieve the loss of the perpetrator, particularly if it is someone with whom they had a positive relationship (Grosz et al., 2000; Hill, 2003; Saunders \& Meinig, 2005).

Siblings may also react to the CSA with an increase in externalizing behaviors. Parents report increased levels of defiance and noncompliance following disclosure (Hill, 2003; Levitt et al., 1991). As previously noted, the sibling may experience anger toward the perpetrator, the victim, or the non-offending caregiver (Grosz et al., 2000). At times, families elect not to share the disclosure immediately with siblings (Hill, 2003); although often well-intentioned, this can lead to feelings of hurt or anger, especially if the siblings learn of the abuse in other contexts. Bentovin (1991) argued that it was tantamount to abuse itself to not inform the sibling of the CSA. Anecdotally, siblings have also expressed blame or resentment toward the victim for causing the abuse or causing the perpetrator's absence from the family. This attribution of responsibility may lead to increased sibling and family conflict, similarly seen in studies examining sibling response to other family members' problem behaviors (Jacoby \& Heatherington, 2016).

The perception of differential attention may also lead to increased internalizing and externalizing symptoms. Perpetrators often engage in grooming behaviors, where they may provide increased praise and attention to the victim (e.g., Craven, Brown, \& Gilchrist, 2006). Anecdotally, siblings have expressed that this increased praise and attention has led them to feel jealous of their victimized sibling. Similarly, the nonoffending caregiver and other important adults may react to disclosure 
by giving the victim a great deal of attention, further contributing to the perception of differential treatment. Increased stress on the part of the non-offending caregiver may also reduce the amount of attention the caregiver is able to give to the sibling. Research on sibling interactions has demonstrated that differential parental treatment is associated with greater levels of sibling conflict and antagonism and less sibling warmth (Brody, Stoneman, \& McCoy, 1992; Buist et al., 2013; Dirks et al., 2015; Richmond, Stocker, \& Rienks, 2005; Shanahan, McHale, Crouter, \& Osgood, 2008). Further, differential treatment and the social comparison associated with differential treatment has been associated with more internalizing symptoms (Jensen et al., 2015), though there is a stronger association for younger children than older children (Buist et al., 2013). Although not abuse-specific, girls who reported less parental warmth than their sibling tended to report higher depressive symptoms (Shanahan et al., 2008). This is also consistent with the literature on children who have siblings with chronic illnesses, who experience negative effects in part due to parental inattention (e.g., Sharpe \& Rossiter, 2002). Thus, as siblings recognize that the victim is getting increased attention, they are more likely to experience negative consequences.

\subsection{Family stress and disruption}

Family stress following disclosure can also influence the sibling's response and behavior. Siblings may be acutely aware of increased parental stress and may want to avoid being a burden, and caregivers may struggle to see the impact of the CSA on the sibling because of their own emotional response. Similar reactions are seen in children following sibling or parental bereavement (Dickens, 2014).

Family dynamics may also change rapidly and divisive rifts can occur if some family members do not believe or support the child victim. In cases of intrafamilial CSA, victims can experience shame by extended family members, leading to a loss of those relationships both for the victim and for the supportive caregivers (Kogan, 2004). Siblings can also be negatively affected by the family disruption and loss of these relationships. Research on emotional abuse and physical abuse in childhood has demonstrated that the negative impact of early childhood adversity on family relationships, including less emotional closeness, extends well into adulthood (Savla et al., 2013). Jonzon and Lindblad (2004) found that among victims of intrafamilial CSA, more than half had 
broken contact with the offender as adults. Further, severe abuse was more strongly associated with loss of contact with other family members as well. This can put the sibling in a precarious situation, trying to balance fractured family relationships. Even in cases of extrafamilial abuse, the offender is typically someone close to the family (Friedenberg et al., 2013). The offender's violation of trust and security impacts all members of the family following disclosure and can lead to relationship difficulties later in life.

Research has found that intrafamilial abuse is associated with greater negative outcomes for victims (Murray et al., 2014; Stroebel et al., 2012; Swenson \& Hanson, 1998). The literature has suggested that intrafamilial CSA tends to occur in families that are more disorganized and chaotic, have increased psychosocial stressors, and are more socially isolated compared to families without CSA and to families with extrafamilial offenders (Levitt et al., 1991; Ray, Jackson, \& Townsley, 1991; Seto et al., 2015; Swenson \& Hanson, 1998; Wright, 1991). Many of these same factors, including parent-child relationship conflict, divorce, and low family cohesion, are associated with increased likelihood of depression (Lewinsohn et al., 1994). Further, high levels of parental conflict have been associated with higher levels of sibling conflict, particularly for younger siblings (Shanahan et al., 2008). It is likely that these factors, along with the abuse itself, contribute to the poorer outcomes seen among intrafamilial abuse victims. Because many of these factors reflect the broader family environment, siblings are likely at increased risk for greater negative outcomes as well.

\subsection{Practical consequences}

Following disclosure, the immediate and long-term tangible consequences for the siblings may moderate the experience of distress (Baker et al., 2001; Hill, 2003). First, there may be immediate safety concerns involving contact with the alleged perpetrator, particularly in cases of intrafamilial abuse (Swenson \& Hanson, 1998). Immediately following disclosure, a safety plan may be implemented to ensure the safety of the victim and siblings. This can lead to significant family disruption, such that the perpetrator is not permitted to have contact with the victim or unsupervised contact with siblings (Saunders \& Meinig, 2005). Siblings might experience a variety of negative emotions in response to family disruption or the loss of a caregiver; some may even blame themselves or the 
victim for causing these changes (Baker et al., 2001; Hill, 2003). These immediate reactions are also seen in children whose parents attempted or completed suicide or who experienced sudden bereavement (Brent, Melhem, Masten, Porta, \& Payne, 2012; Dickens, 2014; Hung \& Rabin, 2009). In cases of intrafamilial abuse, the perpetrator may be removed from the home, or the nonoffending family members may need to relocate (Wright, 1991). These physical separations can also lead to more concrete changes for the siblings, including moving schools and neighborhoods or even relocating to another state. Further, in cases where the perpetrator was a caregiver, loss of income may lead to financial stressors that may impact the entire family unit (Swenson \& Hanson, 1998; Wright, 1991).

CSA disclosure can also lead to forensic and legal involvement, which can further impact the sibling's response. As part of an investigation, siblings may have to participate in a forensic interview to gather information about the victim's abuse; this also provides an opportunity for the sibling to disclose their own experience with CSA (Baker et al., 2001; Swenson \& Hanson, 1998). As previously discussed, children tend to be reluctant to disclose abuse, which could lead to multiple forensic interviews if there is suspicion that a sibling experienced CSA as well (Block, Foster, Pierce, Berkoff, \& Runyan, 2013; McElvaney, 2015; Quas \& Goodman, 2011). There may also be Child Protective Services (CPS) involvement depending on the relationship to the perpetrator or the non-offending caregiver's response (Baker et al., 2001; Corcoran, 2004). For example, we periodically work with caregivers who do not believe that their child has experienced abuse and are unwilling to cease contact with the alleged offender. CPS can remove both the victim and sibling from the custody of the non-offending parent if there is reason to believe that the children are at risk of harm. This can lead to additional distress and family disruption (Finkelhor, Cross, \& Cantor, 2005; Ghetti, Alexander, \& Goodman, 2002; Quas \& Goodman, 2011).

In the event that the investigation progresses, legal proceedings and court involvement present an increasing strain on both victims and siblings (Baker et al., 2001; Corcoran, 2004). For younger children in particular, poor understanding of the legal process may be confusing and frightening, leading to increased anxiety (Ben-Arieh \& Windman, 2007; Ghetti et al., 2002; Quas, Wallin, Horwitz, Davis, \& Lyon, 2009). The literature on children's involvement with the legal system, though focused on victims, suggests that the extent of the emotional and behavioral 
response is based on a number of factors, including age and duration of involvement (Back, Gustafsson, \& Bertero, 2014; Quas \& Goodman, 2011). Victims who have been involved in court proceedings are at risk for negative outcomes, including mental health problems and negative responses from others (Ghetti et al., 2002; McElvaney, 2015; Quas \& Goodman, 2011). Sometimes siblings are required to testify in court, which can be particularly challenging if the sibling feels some loyalty to the defendant. However, research on victim court involvement suggests that some victims feel empowered by testifying against their offender and may be relieved if there is a conviction (Back et al., 2014; Quas \& Goodman, 2011). Siblings may similarly feel empowered by their support of the victim.

\subsection{Protective factors}

Although the majority of this section has focused on deleterious responses to CSA, there is heterogeneity in the response that siblings may show to CSA (Pogue \& Hansen, 2016). Extrapolating from the broader literature on sibling relationships, many children who have anxious siblings demonstrate resilience and experience no negative outcomes themselves (Jacoby \& Heatherington, 2016). Supportive families can serve as protective factors following exposure to stressful events. For example, multiple studies have found that youth fared better after exposure to family and community violence when families encouraged emotionfocused coping (Foster \& Brooks-Gunn, 2009; Mohammed, Shapiro, Wainwright, \& Carter, 2014). Children from lower socioeconomic backgrounds who have been exposed to violence but who spend more time with their family report fewer anxiety and depressive symptoms one year following the violence (Hammack, Richards, Luo, Edlynn, \& Roy, 2004). Warm caregiving and caregiver support has been associated with resilience in children who have been exposed to violence or high stress (Bai \& Repetti, 2015; Lamis, Wilson, King, \& Kaslow, 2014).

Some siblings may also demonstrate strong feelings of protectiveness toward the victim and increased supportive behaviors in response to the enhanced needs of the victim (Hill, 2003; Wright, 1991). The increased supportive behaviors displayed by siblings can lead to reduced symptomatology on the part of the victim, as evidenced by the broader literature on sibling relationships (Buist et al., 2013; Gass et al., 2007; Richmond et al., 2005). Positive sibling relationships, characterized by high 
levels of companionship and low levels of conflict, have been shown to protect against the effects of parental psychological distress (Keeton et al., 2015). Children who are bullied but who report warm relationships with siblings also report fewer internalizing and externalizing behaviors (Bowes, Maughan, Caspi, Moffitt, \& Arseneault, 2010; Lamarche et al., 2006). This effect may be particularly salient if the sibling is older than the victim (Pike, Coldwell, \& Dunn, 2005).

These positive responses can be amplified in the context of mental health treatment. Effective treatments have been developed for victims and caregivers (Corcoran, 2004; Murray et al., 2014; Tavkar \& Hansen, 2011). Lamis et al. (2014) suggest that mental health treatment should increase family social support in order to promote positive outcomes. Caregivers are demonstrating a considerable level of support for the victim by seeking mental health treatment for themselves and their families following disclosure. By incorporating siblings in abuse-specific mental health treatment, they might not only feel supported by the caregiver's treatment seeking attitudes, but could also learn skills to further support the victim.

\section{Treatment approaches}

To date, there are only four treatments described in the literature both individual and group - that have been used with siblings of CSA victims. An overview of three of the treatment models is provided below. A more detailed description of the program design and preliminary research evidence for the fourth model, Project SAFE (Sexual Abuse Family Education; Tavkar \& Hansen, 2011), follows.

The Family Learning Program (FLP) provides outpatient group treatment for families who have experienced intrafamilial abuse (Baker et al., 2001). Operating out of the School of Psychology at Florida Institute of Technology beginning in 1992, siblings participate in groups facilitated by students in a doctoral training program. Group content includes psychoeducation about sexual abuse, good and bad touches, emotion identification, and coping skills, along with discussion of personal space, private parts, recognizing red flags and tricks perpetrators use, and assertiveness skills designed to help siblings learn to keep themselves safe (Baker et al., 2001; Family Learning Program, n.d.). However, no research 
on the sibling group has been published or presented since 2003. The most recent published data (Baker et al., 2001) state that over 110 siblings had participated in the treatment program, representing nearly $40 \%$ of participating victims. Anecdotal evidence and early survey data on initial implementations indicate that both parents and siblings found the group treatment to be helpful, with parents identifying their children learning how to handle inappropriate advances as the most important aspect of group (Baker et al., 2001).

The National Society for the Prevention of Cruelty to Children (NSPCC) offers outpatient individual therapy for siblings in families who have experienced CSA in the United Kingdom (Hill, 2003). The only published paper to date on the inclusion of siblings in this program includes four case studies of siblings who were referred by their parents during the course of treatment for the victimized child (Hill, 2003). The case examples provided described the use of non-directive play therapy and workbooks and videos to provide information on sexual abuse and its effects, along with a focus on emotional reactions to changes in the family. In contrast to the FLP, this individualized treatment was not designed for dissemination, and is not standardized or structured. Instead, it covers a variety of topics based on presenting needs.

Another individual treatment option for siblings was briefly discussed as part of the Recovery for Children and Parents program (ReCAP; Grosz et al., 2000). This pilot program, designed for families experiencing extrafamilial sexual abuse, included group treatment for victimized children and non-offending caregivers and individual counseling provided as-needed for siblings. In this pilot study, 12 siblings received services addressing feelings of guilt and responsibility and other emotions toward the perpetrator, such as anger, sadness, loss, and confusion (Grosz et al., 2000). While siblings did not participate in any group treatment, they were periodically included in family sessions in order to review treatment progress. However, no data were provided regarding sibling symptom presentation or treatment outcomes and no subsequent studies using this program have been published to date.

Finally, the Project SAFE Sibling Group Treatment is a short-term group treatment for non-abused, non-offending siblings of sexually abused youth operating out of a local Child Advocacy Center (Sexual Abuse Family Education; Tavkar \& Hansen, 2011). The Sibling Group is a six-week group treatment that runs concurrently with a 12 -week 
group treatment for sexually abused children and their non-offending caregivers (for more information on the Project SAFE group treatment for victims and caregivers, see Hansen, Hecht, \& Futa, 1998; Tavkar \& Hansen, 2011). The use of concurrent services reduces the need to provide childcare for siblings and may address a barrier to treatment engagement for these families. The Sibling Group was developed in 2004 out of recognition of the needs of this population and is currently being evaluated and refined. Services are provided by two co-therapists who are in doctoral training programs and are supervised by a licensed clinical psychologist. Session topics include psychoeducation, identification and regulation of emotions, relaxation techniques, cognitive restructuring, the impact of CSA on the family, sex education, and strategies to prevent victimization (Table 1). Sessions are designed to address the unique experience of CSA for siblings, and content reflects the specific constructs identified in Section 2 of this paper. The Sibling Group treatment also provides an opportunity for siblings to receive support from others who have had similar experiences, thus reducing shame and stigmatization, and allows them to gain a better understanding of the impact of abuse on their family (Pogue et al., 2014).

To further evaluate and refine this program, siblings and their caregivers may also elect to participate in research. Participants complete a battery of well-established measures at pre-treatment, post-treatment, and three-month follow-up. Measures assess both self- and parent-report of broad domains of emotional and psychological functioning, including anxiety, depression, and self-esteem, specific symptoms related to the CSA, and perceptions of how the victim's abuse will affect the sibling in the future. In an initial examination of the Project SAFE Sibling Group, results indicated that while there was heterogeneity of symptom presentation, most siblings presented as sub-clinical on all measures at pretreatment (Schreier et al., 2012). Because the majority of siblings had few symptoms prior to treatment, there were not significant changes in symptom presentation from preto post-treatment. A more recent study delving further into the relationship between sibling, victim, and parent symptom presentation found that sibling distress was significantly associated with the level of victim distress, family cohesiveness, and family problem-solving skills (Pogue \& Hansen, 2016). For example, results indicated that sibling distress (summed self-report scores of symptoms of depression and anxiety) was associated with increased levels of victim 
Table 1 Session summary of Project SAFE Sibling Group

Session title Summary of session

Welcome and Feelings

The purpose of the first session is to build rapport with the group, establish group rules, and discuss confidentiality. The first session focuses on emotion identification in themselves and others and examines the causes and consequences of feelings.

Learning About our Bodies

The second session provides information on "safe" versus "unsafe" touches, "good" versus "bad" secrets, and age-appropriate sexual development. Personal space is discussed.

My Family \& Offenders

The third session discusses the impact of the abuse and disclosure on the family. Siblings discuss their families and other forms of social support. Information is provided about offenders.

Learning to Cope with My Feelings The fourth session focuses on exploring the relationship between feelings and behavior. Siblings continue to identify sources of social support. Coping strategies for handling negative thoughts and feelings are discussed. The fifth session aims to teach siblings strategies to prevent the occurrence of abuse. Siblings role-play problem solving and assertiveness. Information is provided about common tricks offenders may use.

Standing up for Your Rights

The fifth session aims to teach siblings strategies to prevent the occurrence of abuse. Siblings roleplay problem solving and assertiveness. Information is provided about common tricks offenders may use.

Good-bye

The sixth session reviews group content and discusses safety rules for the sibling and his/her family. Siblings are given an opportunity to provide feedback about the group and group content.

distress (Pogue \& Hansen, 2016). Higher sibling distress was also correlated with lower perceived family cohesion (Pogue \& Hansen, 2016). Sibling distress was significantly and positively associated with victim report of PTSD symptoms, particularly with hyperarousal and intrusive thoughts (Pogue \& Hansen, 2016). Even when controlling for the level 
of victim distress, higher sibling distress predicted a lower sense of parental competency (Pogue \& Hansen, 2016). These results suggest that non-abused siblings may be particularly impacted by impairments in family functioning and by other family members' symptoms of distress; both of which frequently follow the experience of CSA. Although the current research evidence is limited, anecdotal evidence and results of a post-treatment social validity questionnaire have also supported the inclusion of siblings in treatment. Siblings report that they appreciate the support they receive from other siblings, parents report that their children benefit from discussing their experiences in the group setting, and victims identify valuing their sibling's participation in group (Schreier et al., 2012).

\section{Challenges and recommendations for future directions}

Despite the knowledge that CSA impacts the entire family, there has been a striking lack of research on non-abused, non-offending siblings. This may reflect numerous methodological challenges that limit the ability to conduct research on the effectiveness of treatment approaches for this population.

Although there is heterogeneity of response, the preliminary findings of the Project SAFE Sibling Group treatment indicate that much of this population presents as asymptomatic on clinical measures of pretreatment functioning. This is to be expected, because siblings are not necessarily presenting to treatment because of known symptoms, but rather because of something their family has experienced. Inclusion of asymptomatic children in treatment is a challenge for researchers and clinicians and is not unique to siblings of victims of CSA. Despite this challenge, an evaluation of the Project SAFE group treatment for victims found that victims who presented with subclinical symptomatology did experience a linear decrease in symptoms over the course of treatment, suggesting that providing treatment to this population is not harmful or damaging and may be beneficial despite statistical insignificance (Sawyer \& Hansen, 2014). Yet, if siblings are not displaying outward symptoms of distress, parents may overlook their needs and may not identify the importance of services (Baker et al., 2001), which could potentially lead to increased difficulty or risk for victimization later in life (BoneyMcCoy \& Finkelhor, 1995; Tavkar \& Hansen, 2011). 
The frequency of subclinical symptomatology may reflect the fact that there are currently no measures specific to the experience of CSA for siblings. Non abuse-specific selfand parent-report measures that can assess broad psychological functioning include measures such as the Child Behavior Checklist (CBCL; Achenbach, 1991; Achenbach \& Rescorla, 2001), the Youth Self Report version (YSR; Achenbach, 1991; Achenbach \& Rescorla, 2001), the Child Depression Inventory (CDI; Kovacs, 1992), and the Children's Manifest Anxiety Scale Revised (RCMAS; Reynolds \& Richmond, 1985). Current abuse-specific measures for victims include measures such as the Children's Impact of Traumatic Events Scale - Revised (CITES-R; Wolfe, Gentile, Michienzi, Sas, \& Wolfe, 1991) and the Post Sexual Abuse Expectations Scale - Youth (PSAES-Y; Meidlinger et al., 2014). The CITES-R is comprised of 78 items grounded in the specific abuse experience between the victim and perpetrator. Items assess for symptoms of PTSD (i.e., intrusive thoughts, avoidance, hyperarousal, sexual anxiety), attributions about the abuse (i.e., self blame/guilt, personal vulnerability, dangerous world, empowerment), social reactions (i.e., negative reactions by others, social support), and eroticism. The PSAES-Y, developed for Project SAFE, is comprised of 10 items assessing how the victim believes the sexual abuse will affect them in the next year across numerous domains, including relationships with peers and family, school, emotions, and behaviors. Although these two abuse-specific measures may not map directly onto psychological diagnoses like depression, anxiety, or post-traumatic stress disorder, they do indicate heightened emotional responses to traumatic events. It is likely that siblings are presenting as asymptomatic in part because these two abuse-specific measures are designed for victims. One solution may be to modify the language to reflect the siblings' experience related to the victim's abuse. Yet, anecdotal evidence from conversations with Project SAFE Sibling Group participants suggests that while the constructs measured by these victimfocused questionnaires may be similar to those experienced by siblings (e.g., guilt/blame, helplessness, confusion, anger, jealousy), the items do not reflect the nuances of the sibling's experience. For example, while a victim may experience guilt for not having disclosed their abuse, a sibling may experience guilt for not having known or protected their sibling. Thus, simply modifying the language may not fully capture the experience of these emotions for siblings. There is a clear need to develop measures that assess the specific experience of CSA for siblings. 
Beyond methodological challenges, the inclusion of siblings in group treatment also presents practical challenges. As Baker et al. (2001) note, providing services to additional family members requires more staff hours and material. While some programs provide services using volunteer therapists or students in training, the increased demands may be problematic for programs with paid therapists. Perhaps one of the most challenging issues is the financial expense for families. The mental health funding system, including managed care via third party payers typically requires medical necessity as a condition of payment. Siblings with asymptomatic presentations would not be eligible for services through most managed care providers. Although fee-for-service models are alternative options, out of pocket payment may be prohibitive for many families.

Throughout this paper, we have reviewed the literature and presented anecdotal evidence about the consequences of CSA for siblings and the potential mechanisms though which siblings are affected. However, the limited research in this area is largely based on case studies or small sample sizes (Baker et al., 2001; Grosz et al., 2000; Hill, 2003; Pogue \& Hansen, 2016). While the research on sibling relationships and the influence of abuse and other challenging life events suggests that nonabused siblings do experience adverse consequences, there is a need for studies specifically examining sibling emotional and behavioral response to disclosure of abuse. Further, studies that examine the impact of sibling relationships on the victims' emotional functioning following disclosure may also help to refine treatment. This also suggests a need to examine how sibling participation in treatment contributes to the recovery of the victim and the family. If treatment is able to improve sibling functioning, they may be better equipped to provide support to their victimized sibling.

More specifically, there is a critical need to develop and evaluate treatments for non-abused, non-offending siblings. To date, there are only four published treatments that incorporate siblings to any extent. There is a need for additional development, refinement, and evaluation of treatment programs in order to understand what kinds of treatment are effective in addressing siblings' specific emotional needs and improving siblings' response to the victim. To enable this line of research to be effective, future studies should also focus on the development of assessment measures that are specific to the siblings' experience of CSA. This 
should include measures assessing clinical symptomatology, in addition to measures of sibling relationship quality and reactions of siblings to disclosure of abuse. Finally, there is a small body of literature on how cultural differences may impact the response to CSA in victims (e.g., Kenny \& McEachern, 2000). Future studies should explore both cultural and gender differences in regard to sibling response as well.

\section{Conclusion}

There is a clear need for an increased focus on the impact of sexual abuse on non-abused, non-offending siblings. The literature suggests that siblings present with diverse responses following CSA, displaying internalizing and externalizing emotions and behaviors. Sibling response is influenced by a number of factors, including the relationship with their sibling and with the offender. Further, siblings are impacted by changes in family dynamics that may occur following abuse as well as practical consequences that may have significant influence on the quality of siblings' day to day life. To date, there has been a paucity of research and attention focused on how non-abused siblings experience CSA. Research is needed to better understand the impact of CSA on siblings, along with factors that may mediate or moderate this response. Further, it is important to continue incorporating siblings into mental health treatment following abuse. Including non-abused siblings in treatment can provide an opportunity for siblings to process the abuse and subsequent changes in their family, help reduce risk for future victimization, and give the sibling skills to better support their victimized sibling. Research is needed to develop, evaluate, and refine both measures and treatments for nonabused, non-offending siblings. An increased focus in this area may help to improve overall family functioning following abuse.

\section{References}

Achenbach, T. (1991). Integrative guide for the 1991 CBCL/4-18, YSR and TRF profiles. Burlington, VT: University of Vermont, Department of Psychiatry.

Achenbach, T. M., \& Rescorla, L. A. (2001). Manual for the ASEBA School-Age Forms \& Profiles. Burlington, VT: University of Vermont, Research Center for Children, Youth, \& Families. 
Back, C., Gustafsson, P. A., \& Bertero, C. (2014). Parental opinions of their child's experience in the legal process: An interpretative analysis. Journal of Child Sexual Abuse, 23, 290-303. http://dx.doi.org/10.1080/10538712.2014.888117.

Bai, S., \& Repetti, R. L. (2015). Short-term resilience processes in the family. Family Relations, 64, 108-119. http://dx.doi.org/10.1111/fare.12101.

Baker, J. N., Tanis, H. J., \& Rice, J. B. (2001). Including siblings in the treatment of child sexual abuse. Journal of Child Sexual Abuse, 10, 1-16.

Ben-Arieh, A., \& Windman, V. (2007). Secondary victimization of children in Israel and the child's perspective. Annual Review of Victimology, 14, 321-336.

Bentovin, A. (1991). Clinical work with families in which sexual abuse has occurred. In C. R. Hollin, \& K. Howells (Eds.), Clinical approaches to sex offenders and their victims (pp. 179-208). West Sussex, England: John Wiley \& Sons.

Block, S. D., Foster, E. M., Pierce, M. W., Berkoff, M. C., \& Runyan, D. K. (2013). Multiple forensic interviews during investigations of child sexual abuse: A costeffectiveness analysis. Applied Developmental Science, 17, 174-183. http://dx.doi. org/10.1080/ 10888691.2013.836033.

Boney-McCoy, S., \& Finkelhor, D. (1995). Prior victimization: A risk factor for child sexual abuse and for PTSD-related symptomatology among sexually abused youth. Child Abuse \& Neglect, 19, 1401-1421.

Bowes, L., Maughan, B., Caspi, A., Moffitt, T. E., \& Arseneault, L. (2010). Families promote emotional and behavioral resilience to bullying: Evidence of an environmental effect. Journal of Child Psychology and Psychiatry, 51, 809-817. http://dx.doi.org/10.1111/j. 1469-7610.2010.02216.x.

Brent, D. A., Melhem, N. M., Masten, A. S., Porta, G., \& Payne, M. W. (2012). Longitudinal effects of parental bereavement on adolescent developmental competence. Journal of Clinical Child \& Adolescent Psychology, 41, 778-791. http://dx.doi.org/10.1080/ 15374416.2012.717871.

Brody, G. H., Stoneman, Z., \& McCoy, J. K. (1992). Associations of maternal and paternal direct and differential behavior with sibling relationships: Contemporaneous and longitudinal analyses. Child Development, 63, 82-92.

Buist, K. L., \& Vermande, M. (2014). Sibling relationship patterns and their associations with child competence and problem behavior. Journal of Family Psychology, 28, 529-537. http://dx.doi.org/10.1037/a0036990.

Buist, K. L., Dekovic, M., \& Prinzie, P. (2013). Sibling relationship quality and psychopathology of children and adolescents: A meta-analysis. Clinical Psychology Review, 33, 97-106. http://dx.doi.org/10.1016/j.cpr.2012.10.007.

Centers for Disease Control and Prevention (2010, September 20). Adverse childhood experiences (ACE) study: Data and statistics. Retrieved from http:// www.cdc.gov/ace/ prevalence.htm.

Collings, S. J., Griffiths, S., \& Kumalo, M. (2005). Patterns of disclosure in child sexual abuse. South African Journal of Psychology, 35, 270-285.

Corcoran, J. (2004). Treatment outcome research with the non-offending parents of sexually abused children: A critical review. Journal of Child Sexual Abuse, 13, $59-84$. 
Craven, S., Brown, S., \& Gilchrist, E. (2006). Sexual grooming of children: Review of the literature and theoretical considerations. Journal of Child Sexual Abuse, 12, 287-299. http://dx.doi.org/10.1080/13552600601069414.

Criss, M. M., \& Shaw, D. S. (2005). Sibling relationships as contexts for delinquency training in low-income families. Journal of Family Psychology, 19, 592-600. http:// dx.doi. org/10.1037/0893-3200.19.4.592.

Deblinger, E., Hathaway, C. R., Lippmann, J., \& Steer, R. (1993). Psychosocial characteristics and correlates of symptoms distress in nonoffending mothers of sexually abused children. Journal of Interpersonal Violence, 8, 155-168.

Dickens, N. (2014). Prevalence of complicated grief and posttraumatic stress disorder in children and adolescents following sibling death. The Family Journal: Counseling and Therapy for Couples and Families, 22, 119-126. http://dx.doi. org/10.1177/ 1066480713505066.

Dirks, M. A., Persram, R., Recchia, H. E., \& Howe, N. (2015). Sibling relationships as sources of risk and resilience in the development and maintenance of internalizing and externalizing problems during childhood and adolescence. Clinical Psychology Review, 42, 145-155. http://dx.doi.org/10.1016/j. cpr.2015.07.003.

Dunn, J. (2002). Sibling relationships. In P. K. Smith, \& C. H. Hart (Eds.), Blackwell handbook of child development (pp. 223-237). Malden, MA: Blackwell.

Dunn, J., Slomkowski, C., \& Beardsall, L. (1994). Sibling relationships from the preschool period through middle childhood and early adolescence. Developmental Psychology, 30, 315-324.

East, P. L. (2009). Adolescent relationships with siblings. In R. M. Lerner, \& L. Steinberg (Eds.), Handbook of adolescent psychology: Contextual influences on adolescent development (3rd ed.) Vol. 2. (pp. 43-73). Hoboken, NJ: Wiley.

East, P. L., Chien, N. C., Adams, J. A., Hokoda, A., \& Maier, A. (2010). Links between sisters' sexual and dating victimization: The roles of neighborhood crime and parental controls. Journal of Family Psychology, 24, 696-708. http://dx.doi. org/10.1037/a0021751.

Elliott, A. N., \& Carnes, C. N. (2001). Reactions of nonoffending parents to the sexual abuse of their child: A review of the literature. Child Maltreatment, 6, 314-331.

Family Learning Program. (n.d.). Retrieved from http://research.fit.edu/flp/ siblings.php. Foster, H., \& Brooks-Gunn, J. (2009). Toward a stress process model of children's exposure to physical family and community violence. Clinical Child and Family Psychology Review, 12, 71-94. http://dx.doi.org/10.1007/ s10567-009-0049-0.

Finkelhor, D., Cross, T. P., \& Cantor, E. N. (2005). The justice system for juvenile victims: A comprehensive model of case flow. Trauma, Violence \& Abuse, 6, 83102. http://dx. doi.org/10.1177/1524838005275090.

Friedenberg, S. L., Hansen, D. J., \& Flood, M. F. (2013). Epidemiology of child and adolescent sexual abuse. In D. S. Bromberg, \& W. T. O'Donohue (Eds.), Handbook of child and adolescent sexuality: Developmental and forensic 
psychology (pp. 303-324). New York, NY: Elsevier. http://dx.doi.org/10.1016/ B978-0-12-387759-8.00012-X.

Furman, W., \& Buhrmester, D. (1985). Children's perceptions of the qualities of sibling relationships. Child Development, 56, 448-461.

Gamble, W. C., \& Yu, J. J. (2014). Young children's sibling relationship interactional types: Associations with family characteristics, parenting, and child characteristic. Early Education and Development, 25, 223-239. http://dx.doi.org/10.1080/1040 9289.2013.788434.

Gass, K., Jenkins, J., \& Dunn, J. (2007). Are sibling relationships protective? A longitudinal study. Journal of Child Psychology and Psychiatry, 48, 167-175. http://dx.doi.org/10.1111/j.1469-7610.2006.01699.x.

Ghetti, S., Alexander, K. W., \& Goodman, G. S. (2002). Legal involvement in child sexual abuse cases: Consequences and interventions. International Journal of Law and Psychiatry, 25, 235-251.

Goodman-Brown, T. B., Edelstein, R. S., Goodman, G. S., Jones, D. P. H., \& Gordon, D. S. (2003). Why children tell: A model of children's disclosure of sexual abuse. Child Abuse \& Neglect, 27, 525-540. http://dx.doi.org/10.1016/ S0145-2134(03)00037-1.

Graham, L., Rogers, P., \& Davies, M. (2007). Attributions in a hypothetical child sexual abuse case: Roles of abuse type, family response and respondent gender. Journal of Family Violence, 22, 733-745. http://dx.doi.org/10.1007/s10896-007-9121-z.

Grosz, C. A., Kempe, R. S., \& Kelly, M. (2000). Extrafamilial sexual abuse: Treatment for child victims and their families. Child Abuse \& Neglect, 24(1), 9-23.

Hammack, P. L., Richards, M. H., Luo, Z., Edlynn, E. S., \& Roy, K. (2004). Social support factors as moderators of community violence exposure among inner-city African American young adolescents. Journal of Child and Adolescent Psychology, 33, 450462. http://dx.doi.org/10.1207/s15374424jccp3303_3.

Hansen, D. J., Hecht, D. B., \& Futa, K. T. (1998). Child sexual abuse. In V. B. Van Hasselt, \& M. Hersen (Eds.), Handbook of psychological treatment protocols for children and adolescents (pp. 153-178). Mahwah, NJ: Lawrence Erlbaum Associates.

Hershkowitz, I., Lanes, O., \& Lamb, M. E. (2007). Exploring the disclosure of child sexual abuse with alleged victims and their parents. Child Abuse \& Neglect, 31, 111-123. http://dx.doi.org/10.1016/j.chiabu.2006.09.004.

Hill A. (2003). Issues facing brothers of sexually abused children: Implications for profes-sional practice. Child and Family Social Work, 8, 281-290.

Howe, N., \& Recchia, H. (2005). Playmates and teachers: Reciprocal and complementary interactions between siblings. Journal of family psychology, 19. (pp. 497-502), 497-502. http://dx.doi.org/10.1037/0893-3200.19.4.497.

Howe, N., \& Recchia, H. (2014). Sibling relationships as a context for learning and development. Early Education and Development, 25, 155-159. http://dx.doi. org/10.1080/ 10409289.2014.857562.

Howe, N., Ross, H. S., \& Rechhia, H. (2011). Sibling relations in early and middle childhood. In P. K. Smith, \& C. H. Hart (Eds.), The Wiley-Blackwell handbook of childhood social development (pp. 356-372) (2nd ed.). Malden, MA: Wiley. 
Hung, N. C., \& Rabin, L. A. (2009). Comprehending childhood bereavement by parental suicide: A critical review of research on outcomes, grief processes, and interventions. Death Studies, 33, 781-814. http://dx.doi. org/10.1080/07481180903142357.

Jacoby, R. J., \& Heatherington, L. (2016). Growing up with an anxious sibling: Psychosocial correlates and predictors of sibling relationships quality. Current Psychology, 35, 57-68. http://dx.doi.org/10.1007/s12144-015-9360-8.

Jensen, A. C., Pond, A. M., \& Padilla-Walker, L. M. (2015). Why can't I be more like my brother? The role and correlates of sibling social comparison. Journal of Youth and Adolescence, 44, 2067-2078. http://dx.doi.org/10.1007/s10964-015-0327-8.

Jonzon, E., \& Lindblad, F. (2004). Disclosure, reactions, and social support: Findings from a sample of adult victims of child sexual abuse. Child Maltreatment, 9, 190200. http:// dx.doi.org/10.1177/1077559504264263.

Keeton, C. P., Teetsel, R. N., Dull, N. M. S., \& Ginsburg, G. S. (2015). Parent psychopathology and children's psychological health: Moderation by sibling relationship dimensions. Journal of Abnormal Child Psychology, 43, 1333-1342. http://dx.doi.org/10.1007/ s10802-015-0013-z.

Kendall-Tackett, K. A., Williams, L. M., \& Finkelhor, D. (1993). Impact of sexual abuse on children: A review and synthesis of recent empirical studies. Psychological Bulletin, 113, 164-180.

Kenny, M. C., \& McEachern, A. G. (2000). Racial, ethnic, and cultural factors of childhood sexual abuse: A selected review of the literature. Clinical Psychology Review, 20, 905-922. http://dx.doi.org/10.1016/S0272-7358(99)00022-7.

Kogan, S. M. (2004). Disclosing unwanted sexual experiences: Results from a national sample of adolescent women. Child Abuse \& Neglect, 28, 147-165. http:// dx.doi.org/ 10.1016/j.chiabu.2003.09.014.

Kovacs, M. (1992). Children's depression inventory. Toronto, Canada: Multi-Health Systems.

Lamarche, V., Brendgen, M., Boivin, M., Vitaro, F., Perusse, D., \& Dionne, G. (2006). Do friendships and sibling relationships provide protection against peer victimization in a similar way? Social Development, 15, 373-393. http://dx.doi. org/10.1111/j. 1467-9507.2006.00347.x.

Lamis, D. A., Wilson, C. K., King, N. M., \& Kaslow, N. J. (2014). Child abuse, social support, and social functioning in African American children. Journal of Family Violence, 29, 881-891. http://dx.doi.org/10.1007/s10896-014-9639-9.

Lanius, R. A., Vermetton, E., \& Pain, C. (2010). The impact of early life trauma on health and disease: The hidden epidemic. New York, NY: Cambridge University Press.

Levitt, C. J., Owen, G., \& Truchsess, J. (1991). Families after sexual abuse: What helps? What is needed? In M. Q. Patton (Ed.), Family sexual abuse: Frontline research and evaluation (pp. 39-56). Newbury Park, CA: Sage.

Lewinsohn, P. M., Roberts, R. E., Seeley, J. R., Rhode, P., Gotlib, I. H., \& Hops, H. (1994). Adolescent psychopathology: II. Psychosocial risk factors for 
depression. Journal of Abnormal Psychology, 103, 302-315. http://dx.doi. org/10.1037/0021-843X.103.2.302.

Lipovsky, J. A., Saunders, B. E., \& Hanson, R. F. (1992). Parent-child relationships of victims and siblings in incest families. Journal of Child Sexual Abuse, 1, 35-50. http://dx.doi.org/10.1300/J070v01n04_03.

Maniglio, R. (2009). The impact of child sexual abuse on health: A systematic review of reviews. Clinical Psychology Review, 29, 647-657. http://dx.doi.org/10.1016/j. cpr. 2009.008.003.

Many, M. M., \& Osofsky, J. D. (2012). Working with survivors of child sexual abuse: Secondary trauma and vicarious traumatization. In P. Goodyear-Brown (Ed.), Handbook of child sexual abuse: Identification, assessment, and treatment (pp. 509-529). Hoboken, NJ: Wiley.

McElvaney, R. (2015). Disclosure of child sexual abuse: Delays, non-disclosure and partial disclosure. What the research tells us and implications for practice. Child Abuse Review, 24, 159-169. http://dx.doi.org/10.1002/car.2280.

McGuire, S., McHale, S. M., \& Updegraff, K. (1996). Children's perceptions of the sibling relationship in middle childhood: Connections within and between family relationships. Personal Relationships, 3, 229-239.

Meidlinger, K., West, T., Pittenger, S. L., Schreier, A., Pogue, J. K., Flood, M. F., \& Hansen, D. J. (2014). Assessing children's expectations post sexual abuse: Initial psychometric evaluation of a self-report measure. Poster presented at the 48th annual convention of the Association for Behavioral and Cognitive Therapies. Philadelphia: PA.

Mohammed, E. T., Shapiro, E. R., Wainwright, L. D., \& Carter, A. S. (2014). Impacts of family and community violence exposure on child coping and mental health. Journal of Abnormal Child Psychology, 43, 203-215. http://dx.doi.org/10.1007/ s10802-014-9889-2.

Murray, L. K., Nguyen, A., \& Cohen, J. A. (2014). Child sexual abuse. Child and Adolescent Psychiatric Clinics of North America, 23, 321-337. http://dx.doi. org/10.1016/j.chc. 2014.01.003.

O’Brien, M. J. (1991). Taking sibling incest seriously. In M. Q. Patton (Ed.), Family sexual abuse: Frontline research and evaluation (pp. 75-92). Thousand Oaks, CA: Sage.

Pike, A., Coldwell, J., \& Dunn, J. F. (2005). Sibling relationships in early/middle childhood: Links with individual adjustment. Journal of Family Psychology, 19, 523-532. http:// dx.doi.org/10.1037/0893-3200.19.4.523.

Pogue, J. K., \& Hansen, D. J. (2016). Non-offending siblings of child sexual abuse victims: Symptom presentation and relationship with victim distress, parent distress, and family functioning. (Manuscript in preparation).

Pogue, J. K., Schreier, A., West, T., Pittenger, S. L., Meidlinger, K., Flood, M. F., \& Hansen, D. J. (2014). Non-abused siblings of sexually abused youth: Symptom presentation and relationship with victim distress and family functioning. Poster presented at the 48th annual convention of the Association for Behavioral and Cognitive Therapies, Philadelphia, PA. 
Putnam, F. W. (2003). Ten-year research update review: Child sexual abuse. Journal of the American Academy of Child and Adolescent Psychiatry, 42, 269-278. http:// dx.doi.org/ 10.1097/00004583-200303000-00006.

Quas, J. A., \& Goodman, G. S. (2011). Consequences of criminal court involvement for child victims. Psychology, Public Policy, and Law, 18, 392-414. http://dx.doi. org/10.1037/ a0026146.

Quas, J. A., Wallin, A. R., Horwitz, B., Davis, E., \& Lyon, T. D. (2009). Maltreated children's understanding of and emotional reactions to dependency court involvement. Behavioral Sciences and the Law, 27, 97-117. http://dx.doi.org/10. 1002/bsl.836.

Ray, K. C., Jackson, J. L., \& Townsley, R. M. (1991). Family environments of victims of intrafamilial and extrafamilial child sexual abuse. Journal of Family Violence, 6 , 365-374.

Reynolds, C. R., \& Richmond, B. O. (1985). Revised Children's manifest anxiety scale. Los Angeles, CA: Western Psychological Services.

Richmond, M. K., Stocker, C. M., \& Rienks, S. L. (2005). Longitudinal associations between sibling relationship quality, parental differential treatment, and children's adjustment. Journal of Family Psychology, 19, 550-559. http://dx.doi. org/10.1037/08933200.19.4.550.

Saunders, B. E., \& Meinig, M. B. (2005). Immediate issues affecting long-term family resolution in cases of parent-child sexual abuse. In R. M. Reece, R. F. Hanson, \& J. Sargent (Eds.), Treatment for child abuse: Common ground for mental health, medical, and legal practitioners (pp. 36-53). Baltimore, MD: Johns Hopkins University Press.

Savla, J. T., Roberto, K. A., Jaramillo-Sierra, A. L., Gambrel, L. E., Karimi, H., ... Butner, L. M. (2013). Childhood abuse affects emotional closeness with family in midand later life. Child Abuse \& Neglect, 37, 388-399. http://dx.doi.org/10.1016/j. chiabu.2012.12. 009.

Sawyer, G. K., \& Hansen, D. J. (2014). Heterogeneous symptom patterns of sexually abused children in treatment: Understanding the complexity of the problem. Journal of Child Sexual Abuse, 23, 900-917.

Schreier, A., Meidlinger, K. M., Martin, E. K., Hubel, G. S., West, T., ... Hansen, D. J. (2012, November). Development and initial examination of a group treatment for non-offending, non-abused siblings of sexually abused youth. Poster presented at the 46th annual convention of the Association for Behavioral and Cognitive Therapies. National: Harbor, MD.

Sedlak, A. J., Mettenburg, A. P., Basena, M., Petta, I., McPherson, K., Greene, A., \& Li, S. (2010). Fourth national incidence study of child abuse and neglect (NIS-4): Report to congress. Washington, DC: U.S. Department of Health and Human Services, Administration for Children and Families.

Seto, M. C., Babchishin, K. M., Pullman, L. E., \& McPhail, I. V. (2015). The puzzle of intrafamilial child sexual abuse: A meta-analysis comparing intrafamilial and extrafamilial offenders with child victims. Clinical Psychology Review, 39, 42-57. http://dx.doi.org/10.1016/j.cpr.2015.04.001. 
Shanahan, L., McHale, S. M., Crouter, A. C., \& Osgood, D. W. (2008). Linkages between parents' differential treatment, youth depressive symptoms, and sibling relationships. Journal of Marriage and Family, 70, 480-494.

Sharpe, D., \& Rossiter, L. (2002). Siblings of children with a chronic illness: A metaanalysis. Journal of Pediatric Psychology, 27, 699-710.

Slomkowski, C., \& Manke, B. (2004). Sibling relationships during childhood: Multiple perceptions from multiple observers. In R. D. Conger, F. O. Lorenz, \& K. A. S. Wickrama (Eds.), Continuity and change in family relations: Theory, methods, and empirical findings (pp. 293-318). New York, NY: Taylor \& Francis.

Slomkowski, C., Rende, R., Conger, K. J., Simons, R. L., \& Conger, R. D. (2001). Sisters, brothers, and delinquency: Evaluating social influence during early and middle adolescence. Child Development, 72, 271-283. http://dx.doi. org/10.1111/1467-8624.00278.

Smith, D. W., Letourneau, E. J., Saunders, B. E., Kilpatrick, D. G., Resnick, H. S., \& Best, C. L. (2000). Delay in disclosure of childhood rape: Results from a national survey. Child Abuse \& Neglect, 24, 273-287.

Solmeyer, A. R., McHale, S. M., \& Crouter, A. C. (2014). Longitudinal associations between sibling relationship qualities and risky behaviors across adolescence. Developmental Psychology, 50, 600-610. http://dx.doi.org/10.1037/a0033207.

Stroebel, S. S., O'Keefe, S. L., Beard, K. W., Kuo, S., Swindell, S. V. S., \& Kommor, M. J. (2012). Father-daughter incest: Data from an anonymous computerized survey. Journal of Child Sexual Abuse, 21, 176-199. http://dx.doi.org/10.1080/10538712 .2012.654007.

Swenson, C. C., \& Hanson, R. (1998). Sexual abuse of children. In J. R. Lutzker (Ed.), Handbook of child abuse research and treatment (pp. 475-499). New York, NY: Springer. http://dx.doi.org/10.1007/978-1-4757-2909-2.

Tavkar, P., \& Hansen, D. J. (2011). Interventions for families victimized by child sexual abuse: Clinical issues and approaches for child advocacy center-based services. Aggression and Violent Behavior, 16, 188-199.

Tucker, C. J., Updegraff, K. A., McHale, S. M., \& Crouter, A. C. (1999). Older siblings as socializers of younger siblings' empathy. Journal of Early Adolescence, 19, 176198. http://dx.doi.org/10.1177/0272431699019002003.

Tyler, K. A. (2002). Social and emotional outcomes of childhood sexual abuse: A review of recent research. Aggression and Violent Behavior, 7, 567-589. http:// dx.doi.org/10. 1016/S1359-1789(01)00047-7.

U.S. Department of Health and Human Services, Administration for Children and Families, Administration on Children, Youth and Families, \& Children's Bureau (2016). Child maltreatment 2014. Availabl from http://www.acf.hhs.gov/ programs/cb/research-data-technology/statistics-research/child-maltreatment.

Wathen, C. N., \& MacMillan, H. L. (2013). Children's exposure to intimate partner violence: Impacts and interventions. Paediatrics \& Child Health, 18, 419-422. 
Whiteman, S. D., Solmeyer, A. R., \& McHale, S. M. (2015). Sibling relationships and adolescent adjustment: Longitudinal associations in two-parent African American families. Journal of Youth and Adolescence, 44, 2042-2053. http://dx.doi. org/10.1007/s10964-015-0286-0.

Wright, S. (1991). Family effects of offender removal from the home. In M. Q. Patton (Ed.), Family sexual abuse: Frontline research and evaluations (pp. 135-146). Newbury Park, CA: Sage Publications.

Wolfe, V. V., Gentile, C., Michienzi, T., Sas, L., \& Wolfe, D. A. (1991). The Children's impact of traumatic events scale: A measure of post-sexual abuse PTSD symptoms. Behavioral Assessment, 13, 359-383.

Wong, T. M. L., Branje, S. J. T., VanderValk, I. E., Hawk, S. T., \& Meeus, W. H. J. (2010). The role of siblings in identity development in adolescence and emerging adulthood. Journal of Adolescence, 33, 673-682. http://dx.doi.org/10.1016/j. adolescence.2009.11.003.

Yancey, C. T., Hansen, D. J., \& Naufel, K. Z. (2011). Heterogeneity of individuals with a history of child sexual abuse: An examination of children presenting to treatment. Journal of Child Sexual Abuse, 20, 111-127. 